\title{
Consideration of topographic expression for Geopark maps - Case study of the North Ibaraki Geopark
}

\author{
Mamoru KOARAI $^{\mathrm{a},}$ *, Rika IMAIZUMI ${ }^{\mathrm{b}}$ \\ ${ }^{a}$ Ibaraki University, mamoru.koarai.sci@vc.ibaraki.ac.jp \\ ${ }^{b}$ Aero Asahi \\ * Corresponding author
}

Keywords: Geopark map, topographic expression, the North Ibaraki Geopark

\begin{abstract}
:
Geopark is preserving a scientifically valuable topography, a stratum, ecology, culture, history, and archeology. Geopark utilizes these sources for education, study and tourism (Geo tourism), aim at regional vitalization. Geopark is distributing many maps as a pamphlet to tourists. Mokudai and Koarai (2011) suggested that there are some problems in Geopark maps. Maps don't explain geographical background. Maps don't express topography well. Geological maps and Land Condition Maps are not used in Geopark maps. The purpose of this study is to create a map that improved some problems in Geopark map. So the authors classified and evaluated maps that are used at Geopark, and they considered elements that need in Geopark maps.

The authors classified and evaluated maps that are used at 23 areas of Geopark in Japan. They carried out survey that using 3 questionnaires, to know that best how to express topography. As a result, they decided essential elements of create a Geopark map. Studied areas are Lake Senba Geosite, Omiya Terrace Geosite, and Tanakura Fault Geosite in the North Ibaraki Geopark. In these areas, the authors created maps, compared and considered.
\end{abstract}

